\title{
PROCESSO DE REAPROVEITAMENTO DA ÁGUA DA VINHAÇA
}

\section{Fernando Oliveira de Queiroz ${ }^{1}$, Jéssica Oliveira Alves ${ }^{2}$, Deusmaque Carneiro Ferreira $^{3}$, Marcelo Bacci da Silva ${ }^{4}$}

${ }^{1}$ Aluno do Programa de Mestrado Profissional em Inovação Tecnológica da Universidade Federal do Triângulo Mineiro, Uberaba, Brasil.

${ }^{2}$ Aluna de Graduação em Engenharia Química da Universidade Federal do Triângulo Mineiro, Uberaba, Brasil.

${ }^{3}$ Professor Doutor do Programa de Pós-Graduação em Ciência e Tecnologia Ambiental da Universidade Federal do Triângulo Mineiro, Uberaba, Brasil.

${ }^{4}$ Professor Doutor do Programa de Mestrado Profissional em Inovação Tecnológica da Universidade Federal do Triângulo Mineiro, Uberaba, Brasil (bacciuftm@gmail.com)

\section{Recebido em: 02/10/2017 - Aprovado em: 21/11/2017 - Publicado em: 05/12/2017 DOI: 10.18677/EnciBio_2017B117}

\begin{abstract}
RESUMO
A crescente demanda energética, aliada a uma forte conscientização ambiental, faz o bioetanol se consolidar como uma fonte de energia renovável muito promissora. $A$ produção desse biocombustível demanda um alto consumo de água. A escassez das fontes de captação tem propiciado às indústrias do setor sucroalcooleiro a busca por fontes alternativas que possam suprir a demanda hídrica a fim de garantir a sua sustentabilidade de produção. Neste contexto, ações e inovações tecnológicas visando o reaproveitamento hídrico da vinhaça merecem destaques, pelos grandes volumes gerados e possibilidades de aproveitamento da água na etapa de evaporação. O objetivo desse estudo foi avaliar a viabilidade energética para reuso da água do processo de evaporação da vinhaça in natura e filtrada. As amostras de vinhaça coletadas em usina sucroalcooleira foram submetidas à filtração simples. A demanda energética dos processos de evaporação das amostras in natura e filtrada foi determinada em escala laboratorial. O condensado obtido (água de reuso) foi submetido à caracterização físico-química. A etapa de filtração da vinhaça não alterou de forma significativa as propriedades físicas da água de reuso, entretanto, foi notória uma maior concentração de sólidos na vinhaça filtrada, com maior grau Brix e, consequentemente, maior geração de água para reuso. Pode-se afirmar que há viabilidade energética do reuso da água a partir de concentração da vinhaça por filtração simples, podendo utilizá-la para fins menos nobres na indústria sucroalcooleira, reduzindo assim a captação nos corpos d'água.
\end{abstract}

PALAVRAS-CHAVE: Água de reuso; Filtração; Vinhaça.

\section{VINASSE WATER REUSE PROCESS}

\section{ABSTRACT}

Growing energy demand allied with a strong environmental awareness makes bioethanol a very promising source of renewable energy. The production of this biofuel demands a high consumption of water. The shortage of water catchment has enabled the sugar and alcohol industry to seek alternative sources that can meet the water demand to guarantee their production sustainability. In this context, 
technological actions and innovations aiming at the reuse of vinasse are worthy of note, due to the large volumes generated and the possibility of using the water in the evaporation stage. The purpose of this study was to evaluate the energy viability for the reuse of water from the process of evaporation of fresh and filtered vinasse. The samples of vinasse collected in a sugarcane mill were submitted to simple filtration. The energy demand of the samples was determined on a laboratory scale. The obtained condensate (reuse water) was submitted to physicochemical characterization. The filtration stage of the vinasse did not significantly altered the physical properties of the reuse water, however, a higher concentration of solids in the filtered vinasse, with higher Brix degree and, consequently, more generation of water for reuse was evident. It can be stated that there is energy viability of water reuse from vinasse concentration by simple filtration, and it can be used for less noble purposes in the sugar and alcohol industry, thus reducing the uptake in water bodies.

KEYWORDS: Filtration; Reuse water; Vinasse.

\section{INTRODUÇÃO}

O Brasil ocupa atualmente a segunda colocação no ranking de produção de etanol, sendo superado pelos Estados Unidos. A principal matéria-prima no país para a produção de etanol é a cana-de-açúcar, enquanto que no líder mundial essa produção se dá pelo processamento do milho (CHRISTOFOLETTI et al., 2013).

A principal utilização do bioetanol no Brasil é como combustível e chega a representar $44 \%$ do total de gasolina consumida no país (BASSO et al., 2008). Segundo dados da União da Indústria da Cana-de-Açúcar (2016), foi colhida na safra 2015/16 uma área de 9.004 milhões de hectares, com total de cana-de-açúcar moída de 665.586,2 milhões de toneladas, 40,4 \% para produção de açúcar, com produção de etanol total em 30.461.524,5 bilhões de litros; sendo $22,5 \%$ de etanol anidro e $37,1 \%$ de etanol hidratado.

As etapas de processamento da cana-de-açúcar nas usinas necessitam consumir uma grande quantidade de água, conceito este fomentado pelos valores de captação praticados no passado e que graças a técnicas de reuso da água vem diminuindo abruptamente nas últimas décadas. O consumo do recurso estimado em 1990 era de $5,6 \mathrm{~m}^{3}$ por tonelada de cana-de-açúcar processada, já em 2005, esse consumo se mostrou em $1,8 \mathrm{~m}^{3}$, graças a inovações tecnológicas inseridas no mercado sucroalcooleiro (RODRIGUES et al., 2016). A escassez para as fontes de captação tem feito as indústrias canavieiras refletirem sobre alternativas que possam suprir a demanda pelo recurso e garantir a segurança hídrica das mesmas. Neste contexto, ações e inovações tecnológicas visando o reaproveitamento hídrico da vinhaça merecem destaque, pelos grandes volumes gerados e possibilidades de aproveitamento da água pela etapa de evaporação.

A vinhaça é a maior fonte de poluição da indústria sucroalcooleira, sendo removida na base das colunas de destilação. Apesar de mostrar algumas variações em sua composição, a vinhaça é composta por $93 \%$ de água e $7 \%$ de sólidos, dos quais $75 \%$ correspondem a matéria orgânica. Em média são produzidos de 12 a 15 $L$ de vinhaça para cada litro de etanol produzido (SANTOS, 2012).

Como alternativa para o reaproveitamento da água surgiram as plantas de evaporação de vinhaça, tecnologia esta que possibilita a utilização da água contida neste efluente. Foram muitos os problemas enfrentados com as plantas de concentração de vinhaça, inviabilizando por certo tempo o investimento, dentre os 
principais problemas podem-se citar: alto consumo energético, incrustação devido à grande quantidade de sólidos presentes na solução e paradas sucessivas para a limpeza. O objetivo desse estudo foi avaliar a viabilidade energética para reuso da água do processo de evaporação da vinhaça in natura e filtrada.

\section{MATERIAL E MÉTODOS}

\section{Procedimentos de Coleta e Amostragem}

O presente trabalho foi desenvolvido utilizando amostras de vinhaça coletadas na destilaria de uma usina de açúcar e etanol, localizada no município de Uberaba - MG. Foram coletadas, uma vez por semana, aproximadamente três litros de vinhaça (amostra simples), entre os meses de outubro e dezembro de 2016. As coletas foram realizadas em quadruplicatas. Todas as amostras foram armazenadas em frascos plásticos, colocadas em caixa térmica a $4^{\circ} \mathrm{C}$ e transportadas para o local de realização das análises físico-químicas e ensaios de evaporação.

Logo após a coleta das amostras de vinhaça, foram realizadas, no Laboratório de Química da usina, as análises de $\mathrm{pH}$, porcentagem de sólidos solúveis, grau Brix e condutividade. Já os ensaios de evaporação e análises da água de reuso foram conduzidos no Laboratório de Análises Físico-Químicas do Instituto de Ciências Tecnológicas e Exatas da Universidade Federal do Triângulo Mineiro (UFTM) em Uberaba-MG. Todas as análises foram realizadas em triplicata. Para a caracterização da amostra da vinhaça, os seguintes parâmetros foram determinados:

a) Massa Específica: os valores foram determinados pelo método da picnometria. Valores elevados indicam uma maior quantidade de matéria orgânica em sua composição. Para garantir que os valores encontrados fossem adequados, fez-se uma calibração no picnômetro, determinando seu volume real. Os testes de calibração foram realizados utilizando água destilada e a determinação da massa específica ocorreu em condições ambiente.

b) Condutividade: foi utilizado o condutivímetro digital de bancada, da marca DIGIMED modelo DM-22, previamente calibrado. A condutividade elétrica foi expressa em $\mu \mathrm{S} / \mathrm{cm}$, sendo diretamente proporcional à quantidade de íons livres, eletrólitos, existentes na composição química da vinhaça.

c) pH: foi utilizado o pHmetro de bancada digital, marca DIGIMED modelo DM-22. A leitura foi realizada sempre mantendo a amostra sob agitação suave para garantir sua homogeneidade.

d) ${ }^{\circ}$ Brix: representa a quantidade de sólidos solúveis em produtos líquidos, tais como o caldo de cana, melado, melaço, xarope de frutas. Uma unidade de ${ }^{\circ}$ Brix corresponde a $1 \mathrm{~g}$ de sólidos solúveis em suspensão em $100 \mathrm{~g}$ de solução, e a unidade correspondente é $\% \mathrm{~m} / \mathrm{m}$ ou $\% \mathrm{~m} / \mathrm{v}$ à uma determinada temperatura. Utilizou-se um refratômetro digital, marca ANTON PAAR, modelo ABEMAT 200.

e) Sólidos: sólido é o estado da matéria caracterizado pela rigidez, por uma forma própria e pela existência de um equilíbrio com o líquido proveniente de uma fusão (REIN, 2017). As determinações foram feitas com filtração e evaporação de aproximadamente $140 \mathrm{~mL}$ de amostra de vinhaça em um cadinho previamente seco a uma temperatura de $103^{\circ} \mathrm{C}$ a $105^{\circ} \mathrm{C}$ e pesado, até sua massa permanecer constante. A amostra de vinhaça foi filtrada à vácuo em filtro seco e pesado previamente, com poro de diâmetro $\leq 1,2 \mathrm{~mm}$ antes da evaporação. Neste caso, 0 material retido no filtro foi seco a $103^{\circ} \mathrm{C}$ em estufa enquanto o material filtrado foi 
evaporado usando bico de Bunsen e seco a $180^{\circ} \mathrm{C}$ também em estufa, para determinar os sólidos em suspensão e sólidos dissolvidos, respectivamente.

\section{Filtração da Vinhaça}

Um sistema de filtração simples foi empregado, filtrando-se $1 \mathrm{~L}$ da amostra de vinhaça em escala laboratorial, uma alternativa econômica, prática e rápida, dispensando assim, equipamentos de controle de vazão e de nível, diminuindo o custo do trabalho e simplificando o procedimento experimental. O sistema utilizado constitui-se de um único filtro, composto por um elemento filtrante, uma malha de nylon, utilizado para a filtração de caldo de cana na usina, com 200 mesh $(0,074$ $\mathrm{mm}$ ) de abertura, colocado em um funil, instalado em um suporte.

\section{Evaporação da Vinhaça}

A etapa de concentração da vinhaça foi realizada pela sua evaporação através do uso de um ebulidor elétrico comercial, com capacidade para evaporar 1 litro de vinhaça durante 30 minutos. A cada cinco minutos após a solução atingir $90^{\circ} \mathrm{C}$, eram coletados $10 \mathrm{~mL}$ de amostra, a qual era colocada em recipiente hermeticamente fechado e identificados para a realização da leitura do ${ }^{\circ}$ Brix em um refratômetro digital. A análise ocorria de 2 a 3 horas após o experimento, não interferindo assim na qualidade das amostras. No total foram produzidas 12 amostras, sendo seis de vinhaça evaporada in natura e seis de vinhaça evaporada após ser submetida ao processo de filtração simples.

\section{Caracterização Físico-Química da Água de Reuso}

Para a geração de água de reuso a partir da vinhaça, foi utilizado um sistema de evaporação com o auxílio de uma manta aquecedora, que forneceu a energia térmica para $1 \mathrm{~L}$ de vinhaça in natura colocado em um balão volumétrico e submetido à evaporação durante uma hora, conforme mostra a Figura 1. Para a recuperação da água da vinhaça foi acoplado um condensador na saída do balão volumétrico. A água assim coletada foi submetida as análises físico-químicas. $O$ mesmo procedimento foi realizado para a vinhaça filtrada.

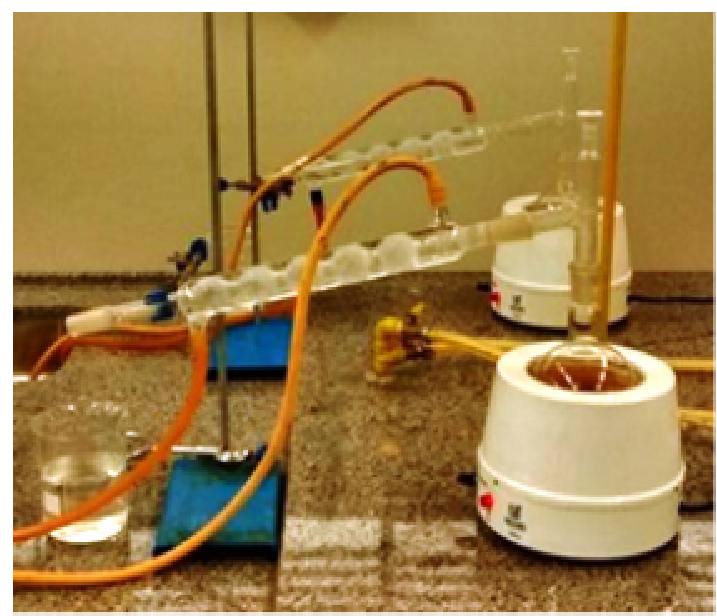

(a)

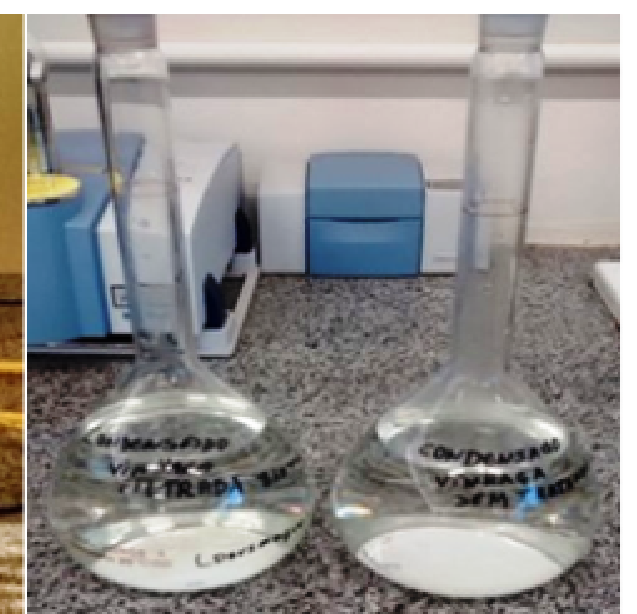

(b)

FIGURA 1 - Esquema de evaporação da vinhaça e recuperação da água de reuso:(a) - Sistema de evaporação com recuperação da água; (b) - Condensado recuperado a ser analisado.

Fonte: Autores, 2017. 
As análises empregadas na caracterização da água de reuso foram: $\mathrm{pH}$, condutividade, turbidez, dureza total, alcalinidade total e cor.

\section{RESULTADOS E DISCUSSÃO}

A Tabela 1 apresenta as leituras, valores médios e desvios padrão calculados para as amostras de vinhaça coletadas que foram utilizadas neste trabalho. Conforme dados da União da Indústria de Cana-de-Açúcar (2016), estes valores podem variar devido a vários fatores, dentre os quais podem-se destacar a composição da matéria-prima, composição do mosto, a fermentação e a destilação. Rodrigues et al. (2016) apresentaram valores de graus Brix para vinhaça in natura variando de 3 a $5 \%$, valores estes bem próximos aos encontrados neste trabalho.

$\mathrm{O}$ resultado encontrado para $\mathrm{o} \mathrm{pH}$ foi idêntico ao resultado encontrado por Moraes et al. (2014), onde foram apresentados valores de $\mathrm{pH}$ em vinhaça oriunda de mosto (caldo/méis) variando de 4,4 a 4,6.

TABELA 1 - Valores e média do $\mathrm{pH}$, graus Brix e condutividade das amostras de vinhaça.

\begin{tabular}{cccc}
\hline Amostra & Graus Brix & Condutividade & pH \\
\hline I & 3,30 & 8,922 & 4,72 \\
II & 2,09 & 6,332 & 4,67 \\
III & 2,90 & 9,717 & 4,67 \\
Resultado & $2,76 \pm 0,63$ & $8,32 \pm 1,77$ & $4,68 \pm 0,03$
\end{tabular}

Fonte: Autores, 2017.

A Tabela 2 apresenta os resultados dos graus Brix em função do tempo de evaporação para as amostras de vinhaça filtrada e in natura.

TABELA 2 - Elevação dos graus Brix durante a etapa de evaporação.

\begin{tabular}{ccc}
\hline $\begin{array}{c}\text { Tempo } \\
\text { (minutos) }\end{array}$ & $\begin{array}{c}\text { Graus Brix médio } \\
\text { Vinhaça filtrada }(\%)\end{array}$ & $\begin{array}{c}\text { Graus Brix médio } \\
\text { Vinhaça in natura }(\%)\end{array}$ \\
\hline 5 & $3,12 \pm 0,84$ & $2,92 \pm 0,34$ \\
10 & $3,94 \pm 0,95$ & $3,46 \pm 0,39$ \\
15 & $5,36 \pm 1,21$ & $4,42 \pm 0,67$ \\
20 & $6,96 \pm 1,54$ & $5,36 \pm 0,86$ \\
25 & $9,01 \pm 2,14$ & $6,90 \pm 1,32$ \\
30 & $15,03 \pm 3,86$ & $9,53 \pm 2,49$
\end{tabular}

Fonte: Autores, (2017).

Foi verificado que a vinhaça in natura possui baixos teores de sólidos, os quais variaram de 2,58 a $12,02 \%$ em função da matéria prima utilizada. O efeito da evaporação provoca uma elevação dos graus Brix e, consequentemente, uma redução de seu volume, sendo esta técnica importantíssima no ponto de vista ambiental, pois possibilita a reutilização da água gerada, no processo industrial 
(ORTEGÓN et al., 2016). A Figura 2 representa o comportamento da concentração em graus Brix ao longo dos 30 minutos de evaporação da vinhaça in natura e da vinhaça filtrada.

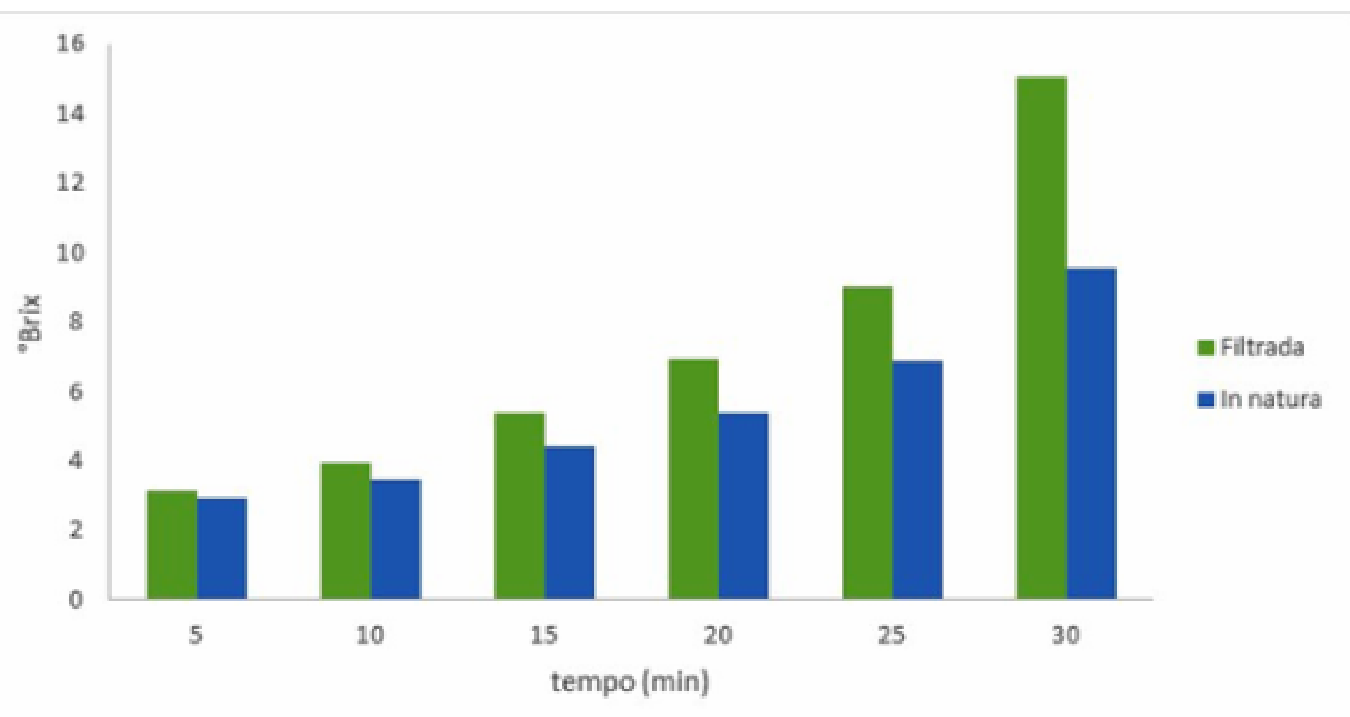

FIGURA 2: Concentração em graus Brix, referente a etapa da evaporação da vinhaça in natura e filtrada.

Fonte: Autores, 2017.

Percebe-se que a vinhaça, após ser filtrada, obteve uma maior concentração devido a solução estar praticamente livre de partículas em suspensão, o que atrapalha a troca térmica e, consequentemente, a evaporação.

Houve, portanto, maior redução de volume na vinhaça que foi submetida à filtração simples, gerando assim maior quantidade de água de reuso, o que possibilitaria uma maior redução na captação nos corpos d'água. Pode-se afirmar certamente que os volumes de vinhaça a serem enviados para as lavouras de cana de açúcar serão menores, acarretando assim em economia energética, uma vez que os meios de transporte são grandes consumidores de energia (JADHAV et al., 2013).

As Tabelas 3 e 4, apresentadas a seguir, mostram os valores quantificados para os sólidos que ficaram retidos durante o processo de filtração da vinhaça e os que permaneceram no filtrado da vinhaça, respectivamente. Pela análise dos resultados verifica-se que o filtro conseguiu reter aproximadamente, em média, 2,50 $\mathrm{g}(1,8 \% \mathrm{~m} / \mathrm{m})$ de sólidos da amostra, os quais poderão ser adicionados a outros fertilizantes organominerais provenientes da planta industrial e posterior aplicação nas lavouras de cana de açúcar.

TABELA 3 - Quantidade de sólidos retidos na filtração (g).

\begin{tabular}{cc}
\hline Amostra & Sólidos retidos $\mathbf{~ ( g ) ~}$ \\
\hline I & $2,34 \pm 0,20$ \\
III & $2,73 \pm 0,20$ \\
III & $2,43 \pm 0,20$ \\
Resultado & $2,50 \pm 0,20$ \\
\hline
\end{tabular}

Fonte: Autores, 2017. 
Como já era esperado, o processo de filtração não reteve todos os sólidos, e cerca de 2,0 $\mathrm{g}$ de sólidos permaneceram na amostra de vinhaça, provavelmente compostos por sais e açúcares infermentescíveis, que são misturados ao mosto de caldo de cana para a produção de etanol, resultando na composição da vinhaça.

TABELA 4 - Quantidade de sólidos na amostra de vinhaça após filtração (g).

\begin{tabular}{ccc}
\hline Amostra & Sólidos $\mathbf{( g )}$ \\
\hline I & $2,1975 \pm 0,05$ \\
II & $2,0630 \pm 0,05$ \\
III & $2,1119 \pm 0,05$ \\
Resultado & $2,1241 \pm 0,05$ \\
\hline
\end{tabular}

Fonte: Autores, 2017.

Em estudos sobre a utilização da vinhaça em lavadores de gazes de caldeiras de usinas sucroalcooleiras, Moraes et al. (2014) relatam que a composição da vinhaça de cana de açúcar possuía em média $18420 \mathrm{mg} / \mathrm{L}$ de sólidos dissolvidos totais (SDT) em amostras de usinas do estado de São Paulo. Neste trabalho foram encontrados aproximadamente $16000 \mathrm{mg} / \mathrm{L}$ em média das amostras analisadas. A respeito dos sólidos solúveis totais pode se dizer que este trabalho encontrou um resultado de $11410 \mathrm{mg} / \mathrm{L}$. A Tabela 5 mostra os valores calculados para as concentrações dos sólidos em suspensão total e sólidos dissolvidos totais nas amostras de vinhaça.

TABELA 5- Quantidade de sólidos em suspensão total e sólidos dissolvidos totais nas amostras.

\begin{tabular}{crc}
\hline Amostra & SST $(\mathbf{m g} / \mathbf{L})$ & SDT $(\mathbf{m g} / \mathbf{L})$ \\
\hline I & $10381,89 \pm 1299,51$ & $16534,73 \pm 511,15$ \\
II & $13218,76 \pm 1299,51$ & $15522,71 \pm 511,15$ \\
III & $10630,14 \pm 1299,51$ & $15390,28 \pm 511,15$ \\
Resultado & $11410,63 \pm 1299,51$ & $15815,90 \pm 511,15$ \\
\hline
\end{tabular}

Fonte: Autores, 2017.

Utilizando os valores de leitura (realizada por multímetro) de tensão fornecida da rede elétrica, e da corrente consumida pelo equipamento usado para a evaporação (ebulidor elétrico), pôde-se calcular o valor da energia consumida durante o experimento. Os resultados são apresentados na Tabela 6.

TABELA 6 - Energia consumida para evaporar a vinhaça

\begin{tabular}{cccc}
\hline $\begin{array}{c}\text { Tempo } \\
\text { (Minutos) }\end{array}$ & $\begin{array}{c}\text { Graus Brix } \\
\text { vinhaça filtrada } \\
(\%)\end{array}$ & $\begin{array}{c}\text { Graus Brix } \\
\text { vinhaça in natura } \\
(\%)\end{array}$ & $\begin{array}{c}\text { Energia } \\
\text { consumida } \\
(\mathbf{J})\end{array}$ \\
\hline $\mathbf{5}$ & 3,12 & 2,92 & 308945,40 \\
$\mathbf{1 0}$ & 3,94 & 3,46 & 617890,80 \\
$\mathbf{1 5}$ & 5,36 & 4,42 & 926836,20 \\
$\mathbf{2 0}$ & 6,96 & 5,36 & 1235781,60 \\
$\mathbf{2 5}$ & 9,01 & 6,90 & 1544727,00 \\
$\mathbf{3 0}$ & 15,03 & 9,53 & 1853672,40 \\
\hline
\end{tabular}

Fonte: Autores, (2017). 
Para as duas situações do experimento foram encontrados os mesmos valores de consumo energético. Entretanto, a concentração (graus Brix) na amostra de vinhaça filtrada mostrou-se com valores mais elevados conforme Figura 3.

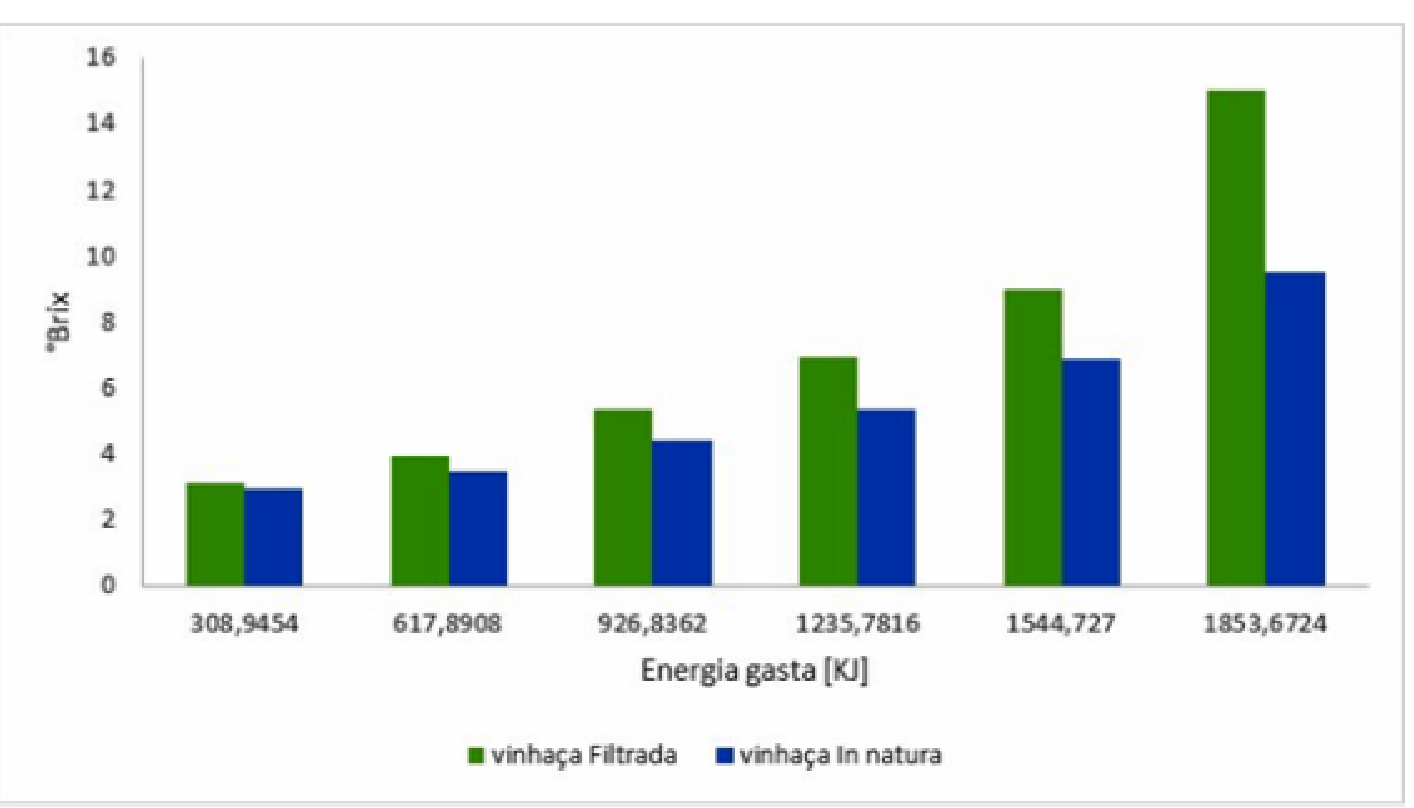

FIGURA 3 - Energia consumida na etapa de evaporação da vinhaça in natura e filtrada.

Fonte: Autores, (2017).

Pode-se afirmar que o processo de filtração da vinhaça para evaporação obteve melhor desempenho frente ao outro processo, evaporação da vinhaça in natura, em função do volume de vinhaça reduzido, diminuindo os gastos com o transporte, e quanto ao volume gerado de água de reuso, diminuindo a captação.

A aplicação e utilização da água em determinadas fases de um processo industrial determinam diferentes tipos de tratamento e respectivos equipamentos, (REIN, 2017). Para atender a demanda qualitativa da água de reuso é essencial entender os processos e realizar análises físico-químicas. A Tabela 7 apresenta os resultados encontrados da água recuperada das amostras de vinhaça, submetidas ao processo de evaporação.

TABELA 7 - Resultados físico-químicos da água de reuso.

\begin{tabular}{lccl}
\hline Parâmetro & $\begin{array}{l}\text { Água da } \\
\text { Vinhaça Filtrada }\end{array}$ & $\begin{array}{c}\text { Água da Vinhaça } \\
\text { In natura }\end{array}$ & Limites \\
\hline pH & $4,50 \pm 0,01$ & $4,50 \pm 0,01$ & $6,8-8,0$ \\
Turbidez $(\mathrm{NTU})$ & $1,95 \pm 0,32$ & $1,81 \pm 0,24$ & Máx 20,0 \\
Dureza total $(\mathrm{ppm})^{*}$ & $75,00 \pm 0,78$ & $70,00 \pm 0,60$ & Máx 40,0 \\
Dureza cálcica $(\mathrm{ppm})^{*}$ & $49,00 \pm 0,28$ & $50,00 \pm 0,29$ & Máx 30,0 \\
Dureza magnesiana $(\mathrm{ppm})^{*}$ & $26,00 \pm 0,50$ & $20,00 \pm 0,42$ & - Máx 60,0 \\
Alcalinidade total $(\mathrm{ppm})^{*}$ & $44,00 \pm 0,40$ & $45,00 \pm 0,36$ & Mán 60,0 \\
Condutividade $(\mu \mathrm{S} / \mathrm{cm})$ & $125,00 \pm 0,10$ & $115,70 \pm 0,22$ & Máx 100,0 \\
\hline
\end{tabular}

"Partes por milhão; " $25^{\circ} \mathrm{C}$

Fonte: Autores, 2017. 
$\mathrm{O} \mathrm{pH}$ da água de reuso ficou na faixa de acidez ( $\mathrm{pH} 4,50)$, isso se deve ao elevado teor de ácidos orgânicos presentes na composição da vinhaça (FREIRE; CORTEZ, 2000). Nesse caso, a correção da acidez é indispensável para a utilização dessa água na planta industrial, uma vez que o meio ácido acelera a corrosão das estruturas metálicas da planta industrial (REIN, 2017).

A água oriunda da vinhaça filtrada e da vinhaça in natura pode ser classificada como moderadamente dura, uma vez que a água muito dura apresenta concentração em carbonato de cálcio superior a $180 \mathrm{mg} / \mathrm{L}$; água dura entre $120 \mathrm{e}$ $180 \mathrm{mg} / \mathrm{L}$, a moderadamente dura entre $60-120 \mathrm{mg} / \mathrm{L}$ e a macia inferior a $60 \mathrm{mg} / \mathrm{L}$ (GRAY, 2008).

Os carbonatos e bicarbonatos de cálcio e de magnésio, que também são responsáveis pela alcalinidade, causam a dureza, que pode variar de zero a centenas de miligramas por litro, dependendo da fonte e do tratamento aplicado. $\mathrm{O}$

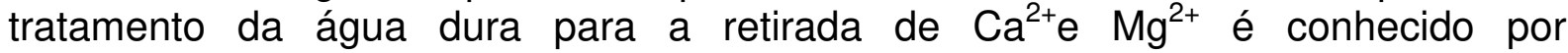
abrandamento e pode ser realizado de duas maneiras: precipitação química e troca iônica (REIN, 2017).

A turbidez é um parâmetro operacional de extrema importância para o controle das etapas de coagulação, floculação, sedimentação e filtração (MOUNTEER, 2008). Entretanto o resultado obtido permite afirmar que não seria necessário aplicar nenhum tipo de tratamento para a remoção da turbidez na água de reuso oriunda da vinhaça. Tendo em vista os benefícios quantitativos alcançados pela filtração da vinhaça para a etapa evaporativa da mesma, a Figura 4 apresenta a inserção da etapa de filtração no processo de produção sucroalcooleiro.

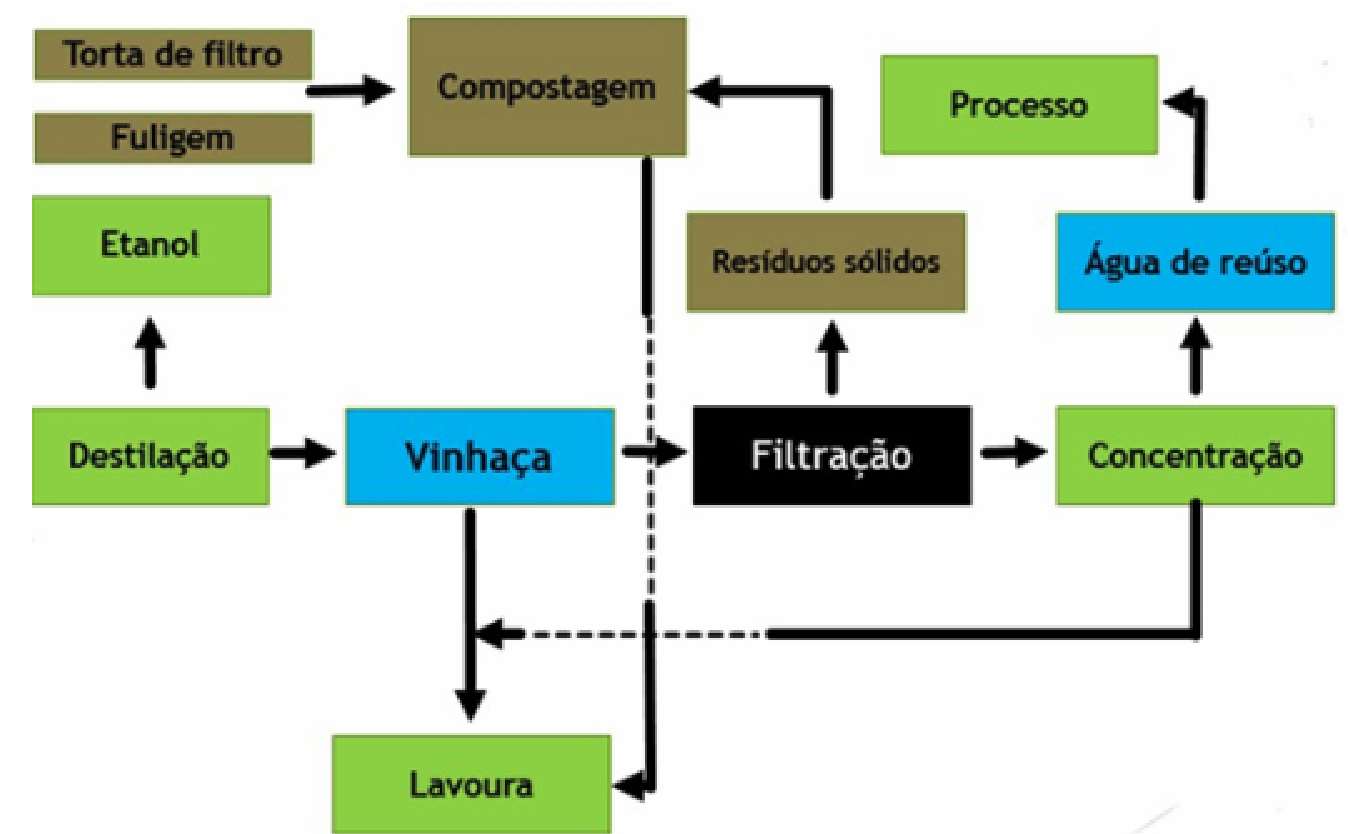

FIGURA 4 - Etapa de filtração da vinhaça no processo de produção sucroalcooleira.

Fonte: Autores, 2017.

Pode-se notar que houve o surgimento de um novo resíduo sólido no processo produtivo, o qual recomenda-se incorporar aos outros existentes, assim haverá um incremento na carga de fertilizantes organominerais oriundos do processo de produção nas usinas sucroalcooleiras. 


\section{CONCLUSÃO}

No estudo desenvolvido foram realizadas etapas de filtração e evaporação da vinhaça em escala laboratorial, analisando-se as propriedades físico-químicas da água gerada, onde foi verificado que a etapa de filtração da vinhaça não alterou as propriedades da água de reuso, entretanto foi notório uma maior concentração dos sólidos solúveis, 15,03 graus Brix na vinhaça filtrada, contra 9,53 graus Brix na vinhaça in natura após as etapas de evaporação. Indica-se assim a filtração simples da vinhaça para uma maior elevação do grau Brix e, consequentemente, maior geração de água para reuso.

Os resultados obtidos no trabalho mostram a possibilidade do reuso da água a partir do processo de concentração da vinhaça de cana de açúcar, podendo-se utilizá-la com fins menos nobres, tais como limpeza geral, reposição de água em torres de resfriamento, ou ainda submetida aos tratamentos para atender as necessidades dos equipamentos ou das etapas do processo. $\mathrm{O} \mathrm{pH}$ manteve-se na faixa ácida de 4,5 e a dureza total de $75 \mathrm{ppm}$, enquanto recomendam-se faixas de 6 a 8 para o pH e no máximo $40 \mathrm{ppm}$ de dureza total. $\mathrm{O}$ consumo energético mostrouse idêntico.

O desenvolvimento sustentável e inovador da indústria canavieira deve ser delineado com base no triângulo economia, sociedade meio ambiente, e para atender à demanda de água, os efluentes devem ser usados como uma ferramenta para a proteção das fontes, maximizando a eficiência e reduzindo a captação nas fontes. Os efluentes devem ser vistos como uma oportunidade, em vez de subproduto.

\section{REFERÊNCIAS}

BASSO, L.C.; De AMORIN, H.V.; De OLIVEIRA, A.J.; LOPES, M.L. Yeast selection for fuel ethanol production in Brazil. Federation of European Microbiological Societies, FEMS Yeast Research, v.8, p.1155-1163, ago. 2008.

doi: 10.1111/j.1567-1364.2008.00428.x.

CHRISTOFOLETTI, C. A.; ESCHER, J. P.; CORREIA, J. E.; MARINHO, J. F. U.; FONTANETTI, C. S. Sugarcane vinasse: Environmental implications of its use. Waste Management, v. 33, issue 12, p. 2752-2761, dec. 2013.

doi: 10,1016/j.wasman.2013.09.005.

FREIRE, W. J.; CORTEZ, L. A. B. Vinhaça de cana-de-açúcar. Guaíba: Agropecuária, 2000. 203p.

GRAY, N.F. Drinking Water Quality: Problems and Solutions. 2nd edition, Cambridge University Press, 2008.

JADHAV, P.G.; VAIDYA, N.G.D.R.; DETHE, S.B. Characterization and comparative study of cane sugar industry wast water. International Journal of Chemical and Physical Sciences, v.2, n.8, p.19-25, 2013.

doi:10.427/ Chemical and Physical Sciences.v2(2).27795

MORAES, B. S.; JUNQUEIRA, T. L.; PAVANELLO, L. G.; CAVALETT, O.; MANTELATTO, P. E.; BONOMI, A.; ZAIAT, M. Anaerobic digestion of vinasse from sugar cane biorefineries in Brazil from energy, environmental, and economic 
perspectives: profit or expense? Applied Energy, v. 113, p. 825-835, january 2014. doi: https://doi.org/10.1016/j.apenergy.2013.07.018.

MOUNTEER, A.H.; NASCIMENTO, L.E. do; BASTOS, R.K.X. CIV-442 Qualidade da água. Apostila de aulas práticas. Universidade Federal de Viçosa-Centro de Ciências Exatas e Tecnológicas - Departamento de Engenharia Civil. Viçosa, 2008.

ORTEGÓN, G. P.; ARBOLEDA, F. M.; CANDELA, L.; TAMOH, K.; VALDESABELLAN, J. Vinasse application to sugar cane fields: Effect on the unsaturated zone and groundwater at Valle del Cauca (Colombia). Science of The Total Environment, v. 539, p.410-419, jan. 2016.

doi: https://doi.org/10.1016/j.scitotenv.2015.08.153.

REIN, P. Cane Sugar Engineering, Verlag Dr. Albert Bartens KG. Berlim, 2017.

RODRIGUES, A.; SANTOS, R. F.; AVACI, A. B.; ROSA, H. A.; CHAVES, L. I.; GASPARIN, E. Estimativa do potencial de geração de energia elétrica a partir da vinhaça. Acta Iguazu, Cascavel, v. 1, n. 2, p. 80-93, 2012. Disponível em: erevista.unioeste.br/index.php/actaiguazu/article/view/7040/5192. Acesso em 14 maio de 2016.

SANTOS, J.D.; SILVA, A.L.L.; COSTA, J.L.C.; SCHEIDT, G.N.; NOVAK, A.C.; SYDNEY, E.B.; SOCCOL, C.R. Development of a vinasse nutritive solution for hydroponics. Journal of Environmental Management, v.114, n.8, p.8-12, 2012. doi.org/10.1016/j.jenvman.2012.10.045.

UNIÃO DA INDÚSTRIA DA CANA DE AÇÚCAR. Moagem de cana de açúcar e produção de açúcar e etanol: safra 2015/2016. Disponível em: <http://goo.gl//A3vim>. Acesso em 15 abril 2016. 